\title{
Management innovation through the formation of corporate memory model
}

\author{
Alexandra Novichkova ${ }^{1, *}$, Olga Malygina ${ }^{2}$, Tatiana Trofimova ${ }^{1}$, Anna Lomovtseva, Valeria Avdonkina ${ }^{1}$ and Olga \\ Rybkina $^{1}$ \\ ${ }^{1}$ Russian Presidential Academy of National Economy and Public Administration (RANEPA), Prospect Vernadskogo, 82, Moscow, \\ 119571, Russian Federation \\ ${ }^{2}$ State University of Management, Ryazanskiy prospect, 99, Moscow, 109542, Russian Federation
}

\begin{abstract}
The Russian Corporation has to work on new principles of functioning in modern social and economic conditions, and implementation of innovative activity is undoubtedly the main and necessary condition which should be created for it. However, innovative activity of the organization depends on maintaining and developing competencies in a straight line, for which, in turn, the corporate memory is needed as a certain framework. In this paper, the role and tasks of corporate memory in the innovation process is considered, its sources are given, and the stages of corporate memory functioning model are presented.
\end{abstract}

\section{Introduction}

In a climate of innovation economy, knowledge is becoming one of the key factors in competitiveness and a source of economic growth [1]. Ensuring innovation activity, creating new knowledge, and realizing it in goods and services triggers an increase in the need for managing knowledge in an organization. Due to the high rate of acceleration in the flow and continuous increase of the information volume, there appears a complication around the issue of retrieving and that of the credibility of information and processing it. The high dynamics of the external environment and changing requirements to the organizational competencies are augmenting the significance of the organization's ability to collect, store, use knowledge, sustain its topicality, and ensure the possibility of employing and spreading knowledge to creating competitive advantages.

Such an ability, based on the experience, traditions, and culture of an organization, is corporate memory, the sources of which are non-formalized (employees' explicit and implicit knowledge) and formalized (stored on paper and electronic data storage devices) organizational knowledge, legislative acts and regulatory materials needed for forming, sustaining, and developing competencies, which are selected based on the criteria of the topicality of knowledge and the possibility of applying and using it in the organization's activity [2].

Despite the availability of studies concerning issues in developing innovation activity within organizations and boosting their competitiveness based on managing knowledge, an integrated approach towards the formation of a model for corporate memory that would ensure the enhancement of knowledge management processes should be developed [3].

Issues related to support of processes of implicit knowledge managing, namely, capturing, accumulating, exchanging, and transforming it into explicit knowledge, as well as formalizing and applying it require special investigation, as it is one of the crucial aspects of energy organizations' management in innovation economy.

\section{The concept and sources of corporate memory}

The term "corporate memory" was proposed by the German scientists Otto Kühn and Andreas Abecker in 1995 to help supporting the corporations' activity (Unilever, Swiss Air, etc.) on managing knowledge and was defined as "a system that encompasses the company's accumulated capacity and other knowledge assets and makes them accessible with a view to boosting the effectiveness of processes of work with knowledge" [4]. The concept of corporate memory is employed in such areas as information technology, knowledge management, and cognitive psychology. In the organizations' management, it is "knowledge of the company's past, including the history of projects, important decisions and rationales behind them, key documents and knowledge of relations with customers". It is realized as a repository of large volumes of data, information, and knowledge from various sources used by the enterprise and is the basis of organizational learning [5]. In the area of information technology, "corporate memory" is considered as the "primary element of the corporate information system". In cognitive psychology, "it is a structured set of

* Corresponding author: ale-novichkova@yandex.ru 
knowledge linked with sustainable experience in the area". The encyclopedia of knowledge management defines "corporate memory" as "the total body of data, information, and knowledge required to deliver the strategic aims and objectives of an organization".

Corporate memory includes explicit and implicit knowledge held by employees, which is non-formalized, as well as formalized knowledge stored on electronic and paper data storages that belong to the organization. If organizational knowledge is accumulated and captured, it becomes an element of the knowledge repository, which can be viewed as a sort of warehouse. The main criterion for including knowledge in the composition of corporate memory is its topicality and the possibility of its practical use through technology for continuously updating and replenishing knowledge using the information-retrieval mechanism, as well as using knowledge in resolving the organization's business objectives.

Thus, the transformation of the knowledge repository into corporate memory takes place through the implementation of ontological and information-retrieval mechanisms that ensure the individual and collective accessibility and mandatory subsequent use of both formalized knowledge and the personnel's knowledge which constitutes the company's past experience [6].

Among the characteristics of corporate memory in the system of managing the organization's knowledge we can point up the following:

1. The integration of knowledge into corporate memory.

2. Capturing knowledge helps prevent committing past errors.

3 . The use of knowledge from corporate memory ensures smooth interaction between the company's business units and the area of work with clients. For instance, in managing interaction with clients in energy companies, one will know who is working with which client and what objectives are being discussed. Besides, if a problem arises it will be easy to pinpoint an employee who has already discussed the issue with a client and will be able to come up with a solution in the shortest time possible. Managing these interactions helps encompassing all channels of contact with clients and serves the client in the same effective way across all the channels. Furthermore, the company is developing smooth interaction between its units.

\section{The role and objectives of using corporate memory in the process of creating innovations}

The organization's competitive advantages are formed based on the creation of innovations (technology, materials, products and services, organizational methods and solutions). Creating innovations involves sustaining and developing the organization's competencies, i.e. ensuring that the level of knowledge meets the challenges of the external environment and that knowledge is topical and valuable to the organization's activity in energy companies.
The organization's competencies are knowledge, skills, or abilities that possess a life-cycle which depends on the uniqueness of this knowledge in a specific area of the organization's activity in a specific market. Competencies can be increased through increases in the degree of mastering knowledge. Competencies, as internal knowledge, are not accessible to the immediate perception of the consumer. They find indirect expression in the use-value of the end-product through the effectiveness of using them and using resources in the organization's activity [7].

The executives of transnational oil and gas British Petroleum Corporation have provided examples of competencies and capabilities which they believe to be the basis of competitiveness of those companies, namely: Personal Drive, Organizational Drive, Managerial Impact, Communication, Awareness of Others, Team Management, Persuasiveness, Analytical Power, Strategic Thinking, Commercial Judgment, Being Able to Adapt [8].

Different organizations, for example, energy companies, have a need for different elements of organizational knowledge, e.g., human and infrastructural resources (e.g. design centers) may be of the highest importance for an organization engaged in research and development. Organizations dealing with distribution of fast-moving consumer goods may prioritize market resources. At the same time, consulting companies may find value in human and market resources, while energy organizations are interested in market and infrastructural ones. Thus, every organization has its own set of top-priority organizational knowledge [9]. Exactly in the same way we differentiate the needs of organizations in terms of capturing, selecting, and using existing knowledge. And for different organizations, top-priority items will be different elements of organizational knowledge, as well as different knowledge management goals and objectives, e.g. retrieval and capture; selection and use; exchange and adaptation, etc. Thus, to resolve these knowledge management objectives, every organization develops its own model for corporate memory.

\section{The formation and functioning of the corporate memory model}

The basis for the capture and use of knowledge in the organization is constructing a model for corporate memory, which is a theoretically constructed aggregate of conceptual notions of the way corporate memory looks and the way it functions in the organization. The need for modeling corporate memory is associated with the following issues: the topicality and significance of knowledge; the complexity of retrieving and accessing it; determining criteria for the choice and selection of knowledge; capturing and using knowledge in innovation activity. Corporate memory is modeled based on the principle of target strategic orientation inclusive of the specificity of the organization's activity and goals, which are expected to be resolved in the organization 
through the formation of a model for corporate memory in the system of managing knowledge.

The key components in developing a corporate memory model are formalized knowledge (on paper and electronic carriers), non-formalized (explicit and implicit) knowledge, which is carried by the organization's employees, and knowledge management instruments and processes: those related to the creation, collection, choice, storage, distribution, exchange, application, development, and protection of knowledge, technology for transforming implicit and explicit knowledge (socialization, externalization, combination, internalization) [10].

The main principle in modeling corporate memory is orientation towards the company's strategic goals and innovation development [11].

The methodology of corporate memory modeling consists of the following stages:

1. A spectrum of relevant knowledge (market, human and infrastructural resources and intellectual property items) is determined based on goals and business objectives formulated in the organization, which are the sources of corporate memory used for forming the company's competencies and boosting its competitiveness.

2. The second stage involves the diagnostics of existing intellectual resources and innovations and determination of their availability in the organization, i.e. the search for knowledge identified in the first stage is performed using all carriers existing in the organization.

3. The next stage involves assessing the conducted diagnostics process, namely: the accessibility of relevant knowledge, the complexity of retrieving it in the company, its topicality, the possibility of using and applying it, including its technical accessibility, the system of communications in the organization, and the employees' motivation towards the exchange of knowledge.

4. Next we perform the comparison of the volume of necessary and existing (accessible for use) intellectual resources and determine the spectrum of missing new knowledge for resolving the set goals and business objectives, the sources and ways of acquiring it. Here we perform the assessment of the degree of complexity of retrieving and acquiring it.

5. Based on stages 2, 3, and 4, we establish the use of technology (information and humanities) for the corporate memory model, depending on the type of knowledge carrier (employees, the repository, paper data storage), which ensures the processes of retrieving, collecting, storing, distributing, exchanging, applying, and using knowledge in organizing innovation activity.

The universal model for corporate memory, which reflects the aims, functions, and results of its formation in the system of managing the knowledge of innovative organizations, is called the functional-structural model.

Table 1. Organization and support for the functioning of the corporate memory model.

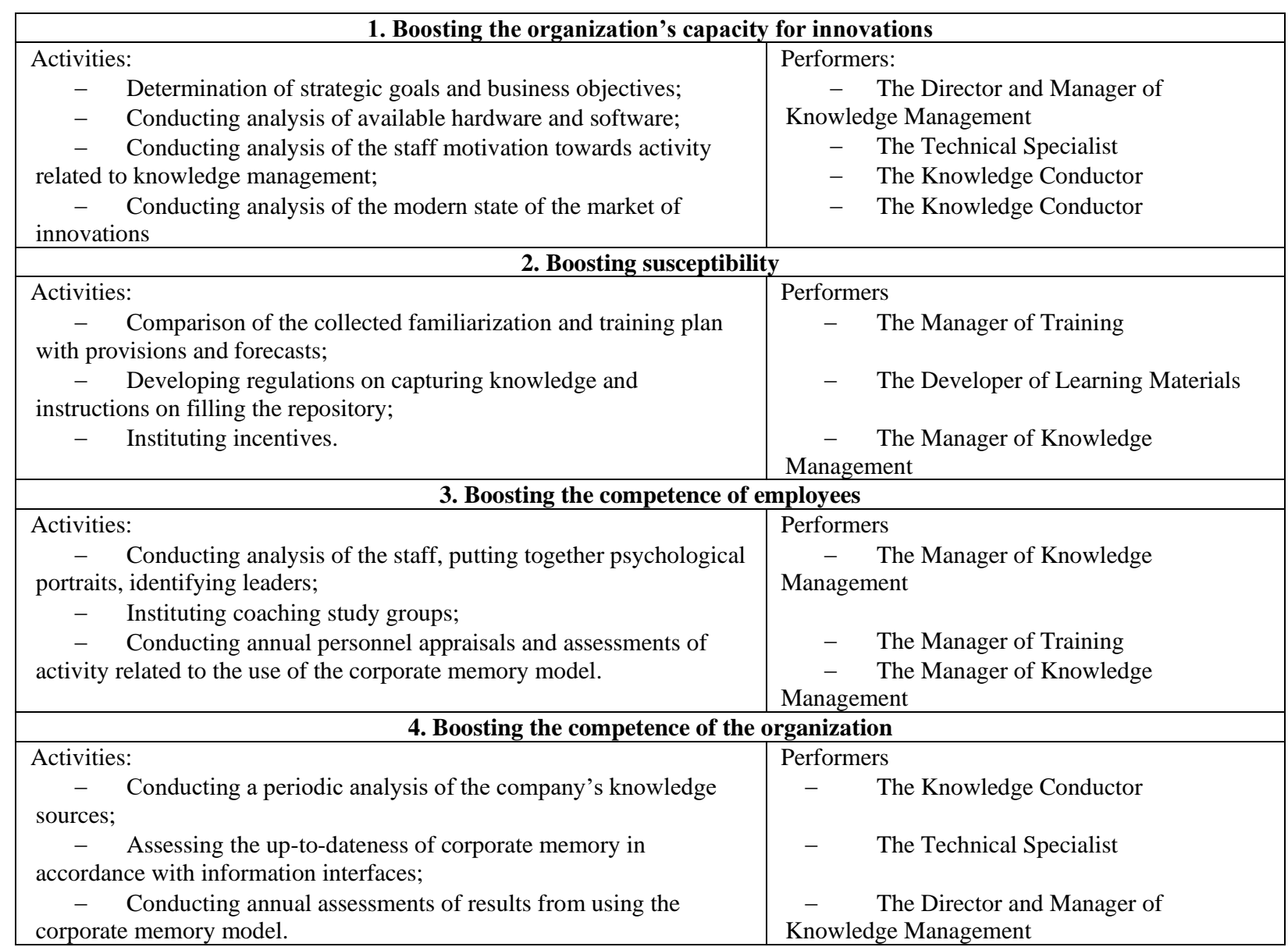




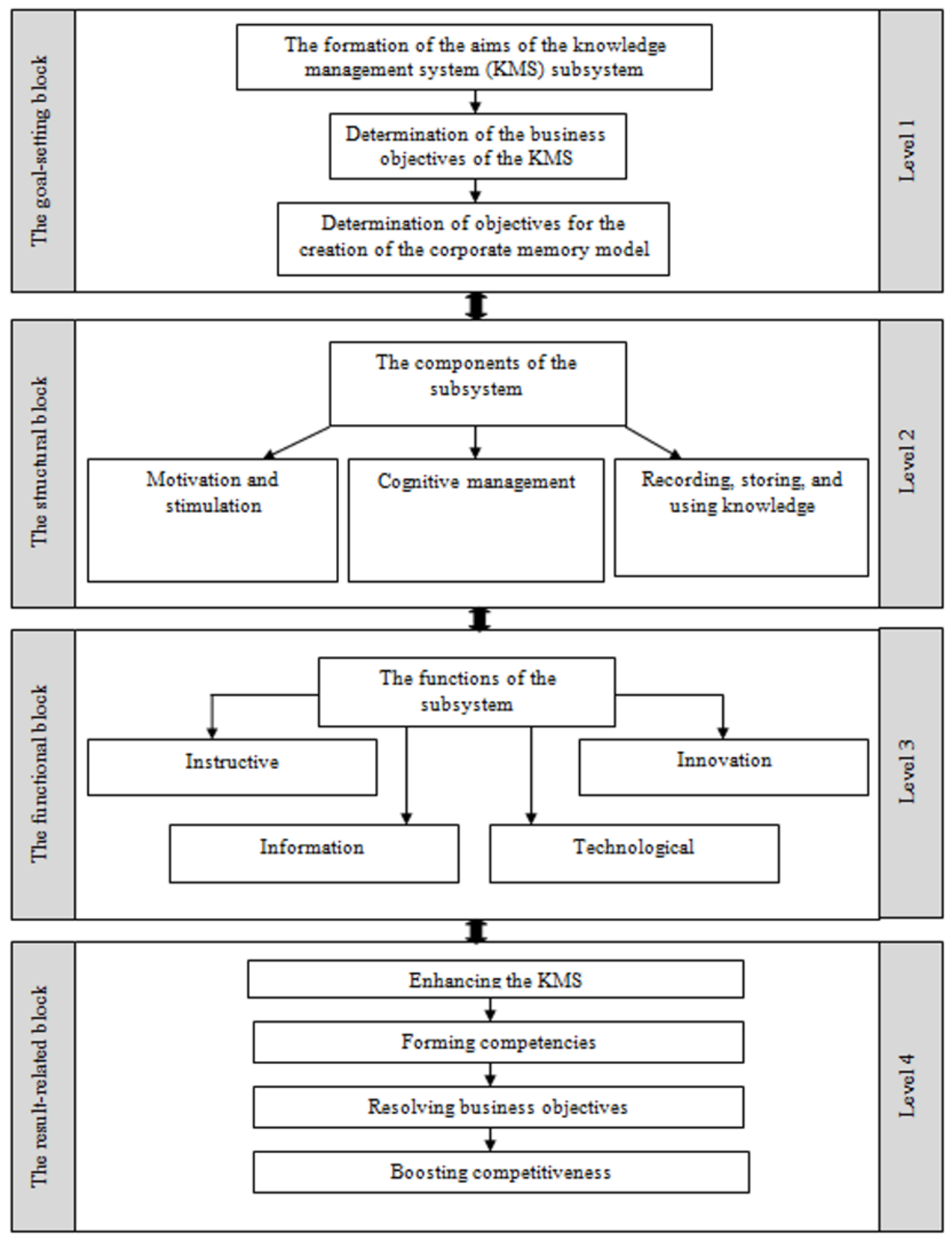

Fig. 1. A functional-structural model for corporate memory.

[12] Marking out components in the model allowed us to divide it into several blocks: goal-setting, structural, functional, and result-related. The blocks are included in the model in hierarchical order, and each of them comes with subsystems.

The goal-setting block subsystem includes the development of a tree of goals consisting of three levels: goals of the knowledge management system, business objectives of the knowledge management system, and objectives for the creation of the corporate memory model.

The components of the structural block subsystem are: motivation, stimulation, and cognitive management, which are related to the development, transformation, and use of employees' knowledge; recording, storing, and using formalized knowledge on paper and electronic carriers [12].

The functional block subsystem should be executed based on the executed functions of corporate memory (instructive, technological, information, and innovation).

The result-related block subsystem includes assessing the results of executing all the functions in terms of enhancing the knowledge management system, forming competencies, resolving business objectives, and boosting competitiveness (Figure 1). 
The realization of the functional-structural model is performed based on an organizational plan that includes stages, processes, and ways of assessing and supporting its functioning in the system of managing the knowledge of innovative companies with a view to ensuring their competitiveness. (Table 1).

Every company is in need of business processes that are optimally organized for them to be able to survive amid global competition in dynamic business environment and in a climate of enhancing innovation activity [13]. All the more important is the company's ability to swiftly and resolutely react to changes in the environment [14]. For that, organizations need to have a common foundation that ensures goal-oriented movement, consisting of a sequence of stages: 1 . boosting the organization's capacity for innovations; 2 . boosting one's susceptibility; 3 . boosting the competence of one's employees; 4 . boosting the competence of the organization.

The stages are realized in the order indicated above, since it is innovations that play a defining role in work with knowledge, and organizations ought to aspire towards boosting their capacity for them to improve their competitive advantages [15]. Each stage consists of processes that include a sequence of activities and their performers (specialists in managing knowledge), which are intended to enhance the company's innovation activity based on support for the functioning of the corporate memory model

Support for the functioning of the corporate memory model is built on three components: organizational, technological, and social, inclusive of increases in the share of the content component of knowledge; increases in the volume of organizational knowledge constituting the organization's experience and practice; the dynamics of the business; improvements in the quality of software support; the dynamics of the topicality of knowledge and the possibility of using it; the emergence of various systems of managing new resources (neurocybernetics, nanotechnology, etc.).

The indicators of the degree to which the organization's innovation activity has been enhanced, which can be achieved through the use of the corporate memory model, are: boosting the business's "intellectuality"; enhancing decision making processes; expanding information competence; creating a common/single environment for partnership; boosting the company's market attractiveness. The above listed indicators are qualitative effects from investing in the formation of a corporate memory model.

The operation of the corporate memory model serves the organization's strategic needs and ensures quick access to knowledge on crucial factors impacting on the attainment of its goals by the company.

Thus, there are new vistas opening up before the company, since the ability to accumulate experience affect the search for and choice of credible new knowledge, and sustain the topicality of knowledge on the projects, products, and services not just of the company itself but of all those taking part in its activity help developing the organizations competencies, create innovations, and acquire and sustain its competitive advantages.

\section{Conclusion}

The proposed functional-structural model, which consists of several interrelated blocks (goal-setting, structural, functional, and result-related), ensures the possibility of getting a more than clear idea of the goaloriented process of formation of a model for corporate memory. The authors recommendations on support for the functioning of the corporate memory model, consisting of going through a sequence of stages and determining the actual performers, within the system of managing knowledge are crucial to the process of enhancing organizations' innovation activity. The article also provides an example of successful management of competencies in TNC British Petroleum in order to improve its competitiveness.

\section{Acknowledgements}

The authors would like to extend their sincere gratitude to Professor Boris Milner, a Corresponding Fellow of the Russian Academy of Sciences and Doctor of Economics, for his help concerning the choice of the study's focus areas and his contribution and support in preparing the work.

\section{References}

1. B.Z. Milner, Innovation Development: Economics, Intellectual Resources, Managing Knowledge (2009)

2. A.V. Novichkova, The Formation of a Model for Corporate Memory within the System of Managing the Knowledge of Innovative Organizations, Candidate thesis (2012)

3. O.V. Malygina, The Formation of the Organization's Competence in the Knowledge Management System, Candidate thesis (2010)

4. A. Abecker, A. Bernardi, K. Hinkelmann, O. Kühn, M. Sintek, Toward a Technology for Organizational Memories (1995)

5. O. Kuhn, Corporate Memories for Knowledge Management in Industrial Practice: Prospects and Challenges (1998)

6. A.V. Raichenko, G.R. Latfullin, Organization Theory (2013)

7. V.Ya. Afanasyev, B.Z. Milner, The Competence of the Organization as a Competitive Advantage (2010)

8. A. Farnham, The Incompetent Manager. Incompetence as Mass Madness (2008)

9. O.V. Malygina, The Competence of the Organization, Chapter 19 in the textbook «Managing Knowledge in an Innovation Economy» (2009)

10. M. Huynh, L. Popkin, Constructing a Corporate Memory Infrastructure from Internet Discovery 


\section{Technologies}

(www.ncsa.uiuc.edu/SDG/IT94/Proceedings/CorInf Sys/huynh/cmi.html.)

11. E.A. Mitrofanova, The Formation of a Model for Competencies: A Methodological Approach, Kadrovik, 8 (2011)

12. M.M. Fischer, Innovation knowledge creation and systems of innovation, The Annals of Regional Science, 2 (2001)

13. Storage management for the information age (2001)

14. Innovative activity of the company, Expertinnovation, 6 (2011) 